\title{
Identifying Interacting Proteins of Arabidopsis Cyclophilin38 (AtCYP38), a Key Factor for PSII Assembly/Repair, via Multiple Screening Approaches
}

Yaqi Hao

Northwest University

Jiashu Chu

Northwest University

Lujing Shi

Northwest University

Cong Ma

Northwest University

Liangliang Hui

Northwest University

Xiaofei Cao

Northwest University

Yuhua Wang

Northwest University

Min Xu

Northwest University

Ai-Gen Fu ( $\nabla$ aigenfu@nwu.edu.cn )

Northwest University https://orcid.org/0000-0002-2036-6443

Research article

Keywords: AtCYP38, Yeast two-hybrid, Chloroplast thylakoid lumen, Interacting proteins

Posted Date: December 8th, 2020

DOI: https://doi.org/10.21203/rs.3.rs-120593/v1

License: () (1) This work is licensed under a Creative Commons Attribution 4.0 International License.

Read Full License 


\section{Abstract}

\section{Background}

AtCYP38, a thylakoid lumen localized immunophilin, is essential for photosystem II (PSII) assembly and maintenance, but how AtCYP38 functions in chloroplast remains unknown. Based on previous functional studies and its crystal structure, we hypothesize that AtCYP38 should function via binding its targets or cofactors in the thylakoid lumen to influence PSII performance. Therefore, identifying its target proteins and cofactors would be a key step to understand the working mechanism of AtCYP38.

Results

To identify potential interacting proteins of AtCYP38, we first adopted two web-based tools, ATTED-II and STRING, and found 15 proteins functionally related to AtCYP38. We then screened a yeast two-hybrid library including an Arabidopsis genome wide cDNA with the N-terminal domain, the C-terminal domain, and the full-length mature protein of AtCYP38. 25 positive targets were identified, but a very limited number of target proteins were localized in the thylakoid lumen. In order to specifically search interacting proteins of AtCYP38 in the thylakoid lumen, we created a yeast two-hybrid mini library including the thylakoid lumenal proteins and lumen fractions of thylakoid membrane proteins. After screening the mini library with 3 different forms of AtCYP38, we obtained 6 thylakoid membrane proteins and 9 thylakoid lumenal proteins as interacting proteins of AtCYP38. We further confirmed the localization of several identified proteins and their interaction between AtCYP38.

\section{Conclusions}

After analysis with two web-based tools and yeast two-hybrid screenings against two different libraries, we identified a couple of potential interacting proteins, which could be functionally related to AtCYP38. We believe that the results will lay a foundation for unveiling the working mechanism of AtCYP38 in photosynthesis.

\section{Background}

In photosynthetic organisms, photosystem II (PSII) is a large multiprotein complex, which is composed of more than 20 protein subunits, many cofactors and pigment molecules on the thylakoid membrane [1, 2]. It catalyzes the light-driven oxidoreduction of water and plastoquinone, and pumps electrons to the photosynthetic electron transfer chain $[3,4]$. Proper biogenesis and maintenance of PSII is essential for photosynthesis in chloroplasts. A large number of auxiliary proteins, including immunophilins in the thylakoid lumen, have been demonstrated to be required for the assembly and/or repair of PSII $[5,6,7]$.

Immunophilins include two groups of proteins without significant sequence homology: cyclophilins (CYPs) and FK506-binding proteins (FKBPs), which are cellular receptors for potent immunosuppressive drugs: cyclosporin A and FK506, respectively $[8,9]$. CYPs and FKBPs share a common feature of peptidyl- 
prolyl cis/trans isomerase (PPlase) activity, which is essential for trafficking and protein folding in cells. These proteins are widely present in prokaryotic and eukaryotic organisms with diverse cellular functions, including mediating protein folding, chaperone activity, scaffold facilitating [10, 11]. In Arabidopsis, a large fraction of immunophilins (17 out of 52 members) are localized in chloroplasts, and interestingly, 16 of the 17 chloroplast immunophilins are presumably present in the thylakoid lumen $[11,12,13]$. Given a small number ( 100) of proteins in the thylakoid lumen proteome and relatively a large number (16) of immunophilins in this compartment $[12,13,14]$, it is reasonable to assume that immunophilins could be functionally related to the assembly and/or maintenance of thylakoid protein complexes. The recent findings that AtCYP38 and AtFKBP20-2 play key roles in PSII assembly and repair confirm the critical physiological roles of immunophilins in the thylakoid lumen $[15,16,17]$.

Arabidopsis cyclophilin38 (AtCYP38) is a greatly divergent immunophilin located in the thylakoid lumen of eukaryotic photosynthetic organisms [18]. Its ortholog in spinach, also named as TLP40, was originally identified as a cofactor of a chloroplast phosphatase [19], and was proposed to function as a negative regulator of a putative thylakoid protein phosphatase [20, 21]. In Arabidopsis, AtCYP38 is indispensable for the correct assembly and rapid repair of PSII $[16,17]$. Arabidopsis mutant plants with a T-DNA disrupted AtCYP38 gene show a stunt growth phenotype and are very sensitive to high light stress [16, 17]. This protein may be required for the proper folding of PSII core proteins D1 and CP43, and the successful assembly of PSII oxygen evolving complex (OEC) [17]. Recently, a study showed that AtCYP38 may negatively regulate PsbO2 activity, and subsequently facilitate the degradation of photo-damaged D1 protein [22]. By far, how AtCYP38 plays its roles in PSIl assembly and maintenance is not clearly understood.

Crystal structure analysis demonstrated that AtCYP38 contains two distinct major domains: an Nterminal a-helical bundle and a C-terminal cyclophilin $\beta$-sheet barrel, with a short acidic loop as a linker in the middle [23]. The two domains are packed together to form a strong intramolecular interaction. This particular structure of AtCYP38 indicates a possible autoinhibition mechanism for its function via the Nand C-terminal interaction. Enzyme activity assay and structure analysis showed that AtCYP38 is not an active PPlase [23]. It is consistent with previous reports that PPlase activity in the thylakoid lumen was strictly attributed to only two immunophilins, AtCYP20-2 and AtFKBP13 [24, 25, 26]. It is likely that AtCYP38 plays important roles in maintaining normal configuration of its substrates with a chaperonelike activity via protein-protein interaction. According to the above comprehensive analysis, searching for partner proteins of AtCYP38 would be of great significance for understanding its working mechanism.

To identify its substrate proteins and potential cofactors, we first carried out the co-expression network ATTED-II [27] and protein-protein interaction network STRING [28] analysis to find potential partner proteins of AtCYP38. Then we performed yeast two-hybrid (YTH) assays to screen against an Arabidopsis genome wide cDNA library with three different forms of AtCYP38. Since AtCYP38 protein is located in the thylakoid lumen, we further constructed an YTH mini library including previously identified lumenal proteins and membrane proteins with lumenal fractions $[12,13,14]$, and screened it with three different forms of AtCYP38. At the end, we confirmed their chloroplast localization of several identified 
proteins and their interactions with AtCYP38. We believe that we obtained certain interacting proteins functionally related to AtCYP38, and it will lay a foundation to understand the possible mechanism on how AtCYP38 plays its roles in the thylakoid lumen.

\section{Results}

\section{Functionally related proteins of AtCYP38 revealed by web-based tools}

In order to search potential interacting proteins of AtCYP38, we first adopted the co-expression network program ATTED-II to search for proteins whose expression pattern is related to AtCYP38. The program revealed 20 proteins are tightly co-expressed with AtCPY38 (Fig. 1A and Table 1). Among these proteins, 8 proteins are localized in the thylakoid lumen, including FKBP18 (At1g20810), PPL (At1g76450), FKPB16-3 (At2g43560), PRP ( At2g44920), PPD6 (At3g56650), TAPX4 (At4g09010), TLP15 (At5g52970), and TLP17.4 (At5g53490); and 1 protein, HHL1 (At1g67700), resides on the thylakoid membrane. Considering the thylakoid lumen localization of AtCYP38, we assumed that these 9 proteins might be functionally related to AtCYP38. Meanwhile, the other 10 co-expression proteins, which are localized in the chloroplast stroma (Fig. 1A and Table 1), are not likely to physically interact with AtCYP38.

In order to evaluate the ATTED-II co-expression results, we also applied the functional protein association tool, STRING, to screen potential proteins related to AtCYP38. The results showed that there are 10 chloroplast proteins functionally related to AtCYP38 at the highest confidence value. Out of these proteins, 4 are localized in the chloroplast thylakoid lumen, including TLP18.3 (At1g54780), PRXQ (At3g26060), MPH2 (At4g02530), and FKBP13 (At5g45680), and 2 proteins, LQY1 (At1g75690) and ATPD (At4g09650), reside on the thylakoid membrane (Fig. 1B and Table 2). All the other proteins are not localized in the chloroplast thylakoid lumen. They might not physically interact with AtCYP38, though they could be functionally related.

After network analysis with these 2 different programs, we found that no protein was co-detected by both software. We assumed that the different results from these two web-based detections could be partially caused by their unique algorithms. Considering their localization and their functions in photosynthesis, we presumed that all these 15 lumen or membrane localized proteins might be functionally related to AtCYP38.

\section{Target proteins screening against a library containing genome wide cDNA}

Yeast two-hybrid (YTH) screening is a powerful and well-established tool to identify interested proteins which could be physically associated with a specific target protein. To identify potential targets and cofactors of AtCYP38, we launched a yeast two-hybrid screening with AtCYP38 as the bait protein. X-ray crystal structural analysis showed that the mature full-length AtCYP38 is composed of an N-terminal ahelical domain and a C-terminal cyclophilin $\beta$-sheet domain, and these two domains could possess different functions [23]. Therefore, we utilized three baits representing different forms of AtCYP38, including the mature full-length protein (CYP38F, without signal peptide), the N-terminal a-helical domain 
(CYP38N), and the C-terminal $\beta$-sheet domain (CYP38C) to perform yeast two-hybrid screening against an Arabidopsis genome wide cDNA library (Fig. 2A).

We screened approximately a total of $2.0 \times 10^{7}$ yeast transformants with these 3 bait proteins, respectively. When CYP38F is used as the bait, we obtained about 70 confirmed positive colonies. After data filtering and interaction confirmation, we found that 8 chloroplast proteins could be interacting partners of AtCYP38 (Fig. 2B, 3A and Table 3). Only 3 proteins were localized in the chloroplast thylakoid lumen, including PSBP-1 (At1g06880), TSP9 (At3g47070) and DEG8 (At5g39830). After screening with CYP38N as the bait, we obtained approximately 50 confirmed positive clones, and further narrowed down to 4 candidate proteins according to their sequence results. However, none of 4 candidate protein was localized in chloroplast (Fig. 2B, 3B and Table 4). Notably, there are a very limited number of positive colonies obtained from screening with CYP38F and CYP38N as baits, indicating that those two baits display a low activity in the YTH screening assay.

When screening the same library with the CYP38C domain, we then obtained about 200 confirmed positive colonies, which were much more than those obtained from screening with CYP38F or CYP38N. After data cleaning up and re-validation, we obtained 15 chloroplast proteins to be interacting candidates of AtCYP38 (Fig. 2B, 3C and Table 5). Interestingly, several chlorophyll binding proteins were identified in this screening, including LHCB1.1, LHCB1.2, LHCB1.5 and LHCB4.1. Other 3 thylakoid membrane proteins, the PSI subunit PASG, the Cytb6f complex subunit PETC, and ROD1[29], an enzyme involved in lipid metabolism, were also found to interact with AtCYP38. Three interacting proteins are thylakoid lumen localized proteins, including PSBP-1, PETE2, and AtCYP38. Notably, PSBP-1 is also a partner of CYP38F. In addition, we also found some proteins are not localized in the thylakoid lumen but still can be identified by yeast two-hybrid assay (Table 5). However, it is unlikely that these proteins physically interact with AtCYP38, considering the different compartmental locations of these proteins and AtCYP38.

It was suggested that the C-terminal domain plays its function to bind other proteins, and the N-terminal bundle domain acts as the regulatory domain, which suppressing AtCYP38 to bind its targets [23]. To test this hypothesis, we cross examined the identified proteins via CDNA library screening with different baits individually. We found that all target proteins screened by CYP38F and CYP38N could interact with CYP38C, but proteins identified from screening with CYP38C could not interact with CYP38F or CYP38N (Fig. 4), which is in agreement with the above assumption.

Altogether, after screening $2.0 \times 10^{7}$ colonies with three different forms of AtCYP38, we obtained a very limited number of potential interacting partners of AtCYP38. Only a few thylakoid lumen proteins were identified in the YTH screening, including PSBP-1, TSP9, DEG8, PETE2 and AtCYP38. We initially expected that a larger number of interacting proteins of AtCYP38 could be identified, given its the chaperone-like activity. The unexpected YTH screening results prompted us to think that screening against a genome wide cDNA library may not be an efficient way to identify the interested interacting proteins. Because proteins in the thylakoid lumen only occupy a very small fraction of the plant cell proteome, it is not surprising that cDNA for thylakoid lumen proteins are relatively rare in this library. Therefore, there exist 
too much noise background due to an overwhelming amount of unrelated proteins in this screening, and consequently, the chance would be very low for AtCYP38 to fish out target proteins which are located in the chloroplast thylakoid lumen.

\section{Yeast two-hybrid screening against a thylakoid lumen protein mini library}

Given that screening the genome wide cDNA library was not a very successful experience, we decided to launch an alternative screening strategy. Since AtCYP38 is a thylakoid lumenal protein, it would be a better choice to screen a library only harboring thylakoid lumen proteins and thylakoid membrane protein with lumenal domains, therefore massive unrelated proteins outside of this compartment would not interfere this screening process.

In order to achieve that, we constructed a yeast two-hybrid mini library harboring a majority of the previously identified lumenal proteins and lumenal domains of various thylakoid membrane proteins. The library was screened against baits including CYP38F, CYP38N and CYP38C, respectively. Interestingly, when we used CYP38F or CYP38N domain to perform the screening, we failed to find any positive potential interacting proteins.

When we used CYP38C to screen the YTH lumenal protein mini library, we obtained 15 potential interacting proteins, including 9 thylakoid lumen soluble proteins, and lumen fragments of 6 thylakoid membrane proteins (Fig. 5, Table 6). In detail, these soluble lumenal proteins are, At1g21500, At2g23670, At2g26340, CTPB (Carboxyl terminal peptidase, At3g57680), CTPA (At4g17740), TLP17.9 (At4g24930), DEG14 (At5g27660), CTPC (At5g46930), and TLP15 (At5g52970). Interestingly, 3 proteases responsible for process the C-terminal extension of D1 precursor (pD1), including CTPA, CTPB, and CTPC were all found to be interacting proteins of AtCYP38. And another protease, DEG14, was also found to interact with AtCYP38. 6 thylakoid membrane proteins whose lumen fragments could be bind to AtCYP38 included PSBM, CYTF, ALB3, CP43, CP47, and PSAF. We assumed that the membrane proteins and those proteases might be substrates of AtCYP38. The result from this screening is consistent with the in vivo function of AtCYP38 in the assembly of PSIl supercomplex $[16,17]$.

\section{Validating localization and in vitro pull-down confirmation assay.}

AtCYP38 is known to be present in the chloroplast thylakoid lumen, and interacting proteins should be in this subcellular compartment as well. In order to verify the localization of candidate proteins, we selected three predicted lumenal proteins, At1g21500, TLP17.9 (At4g24930) and TLP15 (At5g52970), and fused the green fluorescent protein (GFP) tag to their C-terminus. The GFP-fused proteins were transiently expressed in leaf epidermal cells from Nicotiana benthamiana and analyzed by confocal microscopy. As we expected, At1g21500, TLP17.9 and TLP15 are localized in the chloroplast (Fig. 6A).

In order to further confirm the direct interaction between identified proteins with AtCYP38, we selected PSBP-1 and FKBP13 to perform the GST pull-down assays. As shown in Fig. 6B, GST-PSBP-1 and GSTFKBP13 were specifically pulled down by CYP38C-HIS but not GST, confirming the interaction between 
those two proteins and CYP38C in vitro. At the meantime, we also included two proteins with unknown function, At1g21500 and TLP17.9, to confirm their interaction with AtCYP38 by the same method. GST21500 or GST-24930 also can be observed an obvious interaction with CYP38C in the pull-down assay (Fig. 6B). Overall, these results indicated that the interactions between AtCYP38 and our candidate proteins are valid, and our screening strategies are reliable and efficient.

\section{Discussion}

As a key protein functioning in PSII repair and assembly, AtCYP38 should physically interact with its substrate proteins and cofactor proteins to play its roles in the chloroplast thylakoid lumen. Finding its lumenal interacting proteins is a key initial step to understand how AtCYP38 perform its functions. In this study, we applied multiple approaches to identify lumenal proteins potentially interacting with AtCYP38.

From the web-based programs, we obtained 12 thylakoid lumenal proteins and 3 membrane proteins (Table 1 and 2). Screening against a genome wide cDNA library revealed that 5 lumenal proteins (PSBP-1 detected twice) and 8 thylakoid membrane proteins could potentially interact with AtCYP38 (Table 3, 4 and 5). From the screening against thylakoid lumen mini library, we obtained 9 soluble thylakoid lumenal proteins and 6 membrane proteins (Fig. 5, Table 6). We consider that all of these proteins identified by different approaches could be potential interacting proteins of AtCYP38, because they meet functional profiles in assembly and/or maintenance of photosynthetic apparatus.

\section{Possible functional roles of AtCYP38 based on interacting proteins}

Identified interacting proteins of AtCYP38 could be classified into two major groups: thylakoid membrane proteins and thylakoid lumen soluble proteins. Membrane proteins included light harvesting complex proteins (LHCBs), subunit proteins in PSII, PSI, Cytb6f, and ATPase complexes. The identification of PSII components strengthens the conception that AtCYP38 is functionally tightly related to PSII's function. The finding of components in other photosynthetic complexes implied that AtCYP38 might have additional functions other than a restricted role in PSII. The other membrane proteins such as HHL1 (At1g67700), LQY1 (At1g75690), and ALB3B (At2g28800) also probably suggested the multiple roles of AtCYP38 in chloroplast.

Remarkably, several thylakoid lumen proteases, including CTPA, CTPB, CTPC, DEG8, and DEG14 are identified as interacting proteins of AtCYP38. CTPs are responsible for the pD1 C-terminal extension processing, which is an essential step for PSII assembly and repair [30, 31]. DEG8 and DEG14 protein are involved in damaged protein degradation in the chloroplast thylakoid [32,33], indicating that AtCYP38 is very likely to be involved in the photosynthetic apparatus repair process. TAPX4 and PRXQ are essential proteins protecting thylakoid membrane complexes from attack of reactive oxygen species (ROS) [34, 35], showing that AtCYP38 might play a role to response against ROS stress. We also found two thylakoid lumen immunophilins, including FKBP18 and FKBP16-3, to be interacting proteins of AtCYP38, indicating that these proteins could be the working partners of AtCYP38. A number of functionally unknown proteins could interact with AtCYP38, including At1g21500هAt2g23670هAt2g26340هTLP17.9 (At4g24930), TLP15 
(At5g52970), and the phosphatase protein, TLP18.3 (At1g54780) [36, 37]. Especially, TLP15 and TLP18.3 were identified both by the web-based program and the YTH screening. There should be a strong functionally relationship between these two proteins and AtCYP38. The TLP15 protein is also predicted to harbor phosphatase domain, implying a possible phosphatase function in thylakoid lumen. It indicated that AtCYP38 could be involved in protein de-phosphorylation, in agreement with earlier reports that AtCYP38 homolog in spinach is identified in a process of chloroplast phosphatase purification $[19,20$, 21].

\section{The possible working mechanism of AtCYP38}

AtCYP38 protein contains two distinct domains: an N-terminal domain and a C-terminal domain, and these two domains were closely packed to form a strong intramolecular interaction [23]. The N-terminal domain was proposed to be a leucine zipper domain and responsible for the protein-protein interaction [19]. However, in our YTH screening, the N-terminal domain showed a very low affinity to interact with other proteins in YTH screenings. Similarly, the full-length mature AtCYP38 protein also showed a low affinity to interact with other proteins. On the contrary, the C-terminal domain could interact with a substantial number of thylakoid lumen proteins, which could be functionally related to AtCYP38. Therefore, we consider that the C-terminal domain is responsible for binding it functional targets, and the $\mathrm{N}$-terminal domain serves as an inhibitory regulatory domain. The dynamic intramolecular interaction is required for AtCYP38 in vivo function under different energy status in chloroplast. We postulated that thylakoid membrane proteins and proteases in the thylakoid lumen might be substrates of AtCYP38, while the other small lumen soluble proteins would be its cofactors.

In summary, several thylakoid proteins were identified to be functionally related to AtCYP38. It is a good initial step to uncover the working mechanism of AtCYP38 in the thylakoid lumen. We understand this research only lay a foundation for future study to characterize how AtCYP38 works in thylakoid lumen. Next step, we will apply molecular biology, genetics and biochemistry tools to study the functional relationship between AtCYP38 and its partners. For those uncharacterized proteins, we plan to use CRISPR-Cas9 technology to create protein deficiency mutants to explore their physiological function and their relationship with AtCYP38. We anticipated that future research on the partner proteins of AtCYP38 will help us to understand its molecular mechanism.

\section{Methods}

\section{Potential interacting targets prediction}

Co-expression network analysis of AtCYP38 was performed by using the analytical tool of ATTED-II database: http://atted.jp [27], from which the associated gene was analyzed. In this study, genes with lower mutual rank value (MR) were considered as the co-expression network modules. AtCYP38 protein interaction network was analyzed through the STRING database on the website: http://string-db.org [28]. Based on biological functions and localizations, we selected interactors that connected with AtCYP38 using the highest confidence interaction score for further network construction. 


\section{Yeast two-hybrid library screening against genome wide cDNA library}

The mature AtCYP38 protein has two domains: an N-terminal a-helical domain and a C-terminal cyclophilin $\beta$-sheet barrel domain, which linked by an intermediate acidic loop [23]. DNA fragments encoding mature full-length AtCYP38 (residues 92-437), N-terminal domain (residues 92-232), and Cterminal domain (residues 236-437), were cloned into a pGBKT7 vector to generate pGBKT7-CYP38F, pGBKT7-CYP38N and pGBKT7-CYP38C, respectively. They were transformed into host strain AH109 using the modified lithium acetate/PEG method according to the protocol described previously by Fields and Ausubel et al [38,39], and assayed auto-activation tests on a series of nutrient deficient selective plates. The Arabidopsis cDNA library (prey) were transformed into yeast AH109 harboring BD-bait and plated on selective medium for target colonies. Meanwhile, dilution yeast cells spread onto control SD/Leu/Trp plates to make sure the transfer efficiency, the estimate counting results indicated that we have more than $2 \times 10^{7}$ transformants in our three individual screenings. The colonies showing potential interaction on SD/-Leu/Trp/His plates were further assayed on SD/-Leu/Trp/His/Ade selective medium until new colonies were grown up.

The plasmid DNA of candidate positive yeast colonies was extracted according to manufacturer's instructions of TIANprep Yeast Plasmid DNA kit (TIANGEN Biotech, Beijing), and then retransformed back to Escherichia coli to amplify the cDNA inserts. The colonies were then sequenced with T7 primer: TAATACGACTCACTATAGGGCG.

\section{Yeast two-hybrid analysis against lumen protein library}

To identify potential interacting partners for AtCYP38 in the chloroplast thylakoid lumen and on the thylakoid membrane, we constructed a yeast two-hybrid mini library harboring chloroplast lumenal proteins/domains. DNA fragments encoding proteins experimentally identified or predicted to present in the thylakoid lumen [12,13], and domains in the lumen of PSII subunits [40, 41], PSI subunits [42], and Cytb(6)f complex subunits [43] were cloned into the Gal4 AD vector pGADGH. Each AD vector in this library was screened with BD vectors pGBKT7-CYP38F, pGBKT7-CYP38N and pGBKT7-CYP38C individually as described above.

\section{Subcellular localization analysis}

For subcellular localization studies, At1g21500, TLP17.9 and TLP15 coding sequences were recombined into modified pMDC83 destination vector, respectively. The constructs were transfected into Agrobacteria GV3101, and the strains were infiltrated into tobacco (Nicotinana benthamiana) epidermal cell using a needle-less syringe [44]. The GFP fluorescent signal was detected after 48 hours infiltration by using confocal laser scanning microscope. The PCR primers used in this study are listed in supplementary Table 1.

\section{In vitro pull-down assay}


The in vitro pull-down assay was performed according to the protocol as detailed by previous described [45]. Recombinant GST-21500F (mature protein, without signal peptide), GST-TLP17.9F (mature protein, without signal peptide), GST-FKBP13, GST-PSBP-1 or CYP38C-HIS was transformed into E. coli strain BL21 and purified using glutathione or $\mathrm{Ni}$ sepharose beads, respectively. Reaction components were mixed and incubated in $\mathrm{PH} 7.4$ phosphate buffer solution at $4^{\circ} \mathrm{C}$ for 2 hours, the precipitated beads were then washed thoroughly with PBST buffer (PBS buffer with $0.1 \%$ Tween 20). Subsequently, washed beads were eluted and analyzed by SDS-PAGE. The PCR primers used in this study are listed in supplementary Table 1.

\section{Abbreviations}

PSI: photosystem I

PSII: photosystem II

Cytb(6)f: cytochrome b6f complex

CYPs: cyclophilins

FKBPs: FK506-binding proteins

PPlase: peptidyl-prolyl cis/trans isomerase (PPlase)

OEC: oxygen evolving complex

LHCBs: light harvesting complex proteins

ROS: reactive oxygen species

ATTED-II: Arabidopsis thaliana trans-factor and cis-element prediction database

STRING: Search Tool for the Retrieval of Interacting Gene

MR: mutual rank

\section{Declarations}

Ethics approval and consent to participate

Not applicable.

\section{Consent for publication}

Not applicable. 
Availability of data and materials

All the data on the present study has been included in the tables or supplementary tables in this manuscript. The datasets used and/or analyzed in this study are available from the corresponding author on reasonable request.

\section{Competing interests}

Aigen Fu is a member of the BMC plant biology editor board, we declare that we have no other conflicts of interest.

\section{Funding}

This research was financially supported by the National Natural Science Foundation of China to A.F (NO. 31270284 and NO.31471261) and Y.H (NO.31300204), Research fund from Northwest University to Y.H (PR12083 and 12NW22), Shaanxi Provincial Science and Technology Department to Y.H (2019JQ-326). The funders had no role in the design of the experiments, data collection and analysis, data interpretation and also in writing the manuscript.

\section{Authors' contributions:}

A.F. and Y.H. designed research; Y.H. J.C. L.S. L.H. C.M. and X.C. performed research; Y.H. J.C. Y.W. M.X. and A.F. analyzed data; Y.H. M.X. and A.F. wrote the paper with contribution and approval from all authors.

\section{Acknowledgements}

Not applicable.

\section{Author information}

Affiliations: Chinese Education Ministry's Key Laboratory of Western Resources and Modern Biotechnology, Key Laboratory of Biotechnology Shaanxi Province, College of Life Sciences, Northwest University, China P.R.

229 North Taibai Road, Xi'an, Shaanxi 710069, China

Yaqi Hao, Jiashu Chu, Lujing Shi, Cong Ma, Liangliang Hui, Xiaofei Cao, Yuhua Wang, Min Xu, Aigen Fu*

Corresponding authors: Aigen Fu, aigenfu@nwu.edu.cn

\section{References}

1. Umena Y, Kawakami K, Shen JR, Kamya N. Crystal structure of oxygen-evolving photosystem II at a resolution of $1.9 \AA$ A Nature. 2011; 473: 55-60.https://doi.org/10.1038/nature09913 
2. Wei X, Su X, Cao P, Liu X, Chang W, Li M, Zhang X, Liu Z. Structure of spinach photosystem II-LHCII supercomplex at 3.2 Å resolution. Nature. 2016; 534: 69-74. https://doi.org/10.1038/nature18020

3. Nelson N, Yocum CF. Structure and function of photosystems I and II. Annu Rev Plant Biol.2006; 57: 521-65.https://doi.org/10.1146/annurev.arplant.57.032905.105350

4. Barber J. Photosystem II: an enzyme of global significance. Biochem Soc T. 2006; 34: 61931.https://doi.org/10.1042/BST0340619

5. Nixon PJ, Michoux F, Yu J, Boehm M, Komenda J. Recent advances in understanding the assembly and repair of photosystem II. Ann Bot. 2010; 106: 1-16.https://doi.org/10.1093/aob/mcq059

6. Nickelsen J, Rengstl B. Photosystem II assembly: from cyanobacteria to plants. Annu. Rev. Plant Biol. 2013; 64: 609-35.https://doi.org/10.1146/annurev-arplant-050312-120124

7. Lu Y. Identification and roles of photosystem II assembly, stability, and repair factors in Arabidopsis. Front Plant Sci. 2016; 7:168-95.https://doi.org/10.3389/fpls.2016.00168

8. Schreiber SL. Chemistry and biology of the immunophilins and their immunosuppressive ligands. Science. 1991; 251: 283-7.https://doi.org/10.1126/science.1702904

9. Luan S, Kudla J, Gruissem W, Schreiber SL. Molecular characterization of a FKBP-type immunophilin from higher plants. Proc Natl Acad Sci USA. 1996; 93: 6964-

9.https://doi.org/10.1073/pnas.93.14.6964

10. Romano P, Gray J, Horton P, Luan S. Plant immunophilins: functional versatility beyond protein maturation. New Phytol. 2005; 166: 753-69.https://doi.org/10.1111/j.1469-8137.2005.01373.x

11. He Z, Li L, Luan S. Immunophilins and parvulins. superfamily of peptidyl prolyl isomerases in Arabidopsis. Plant Physiol. 2004; 134: 1248-67.https://doi.org/10.1104/pp.103.031005

12. Peltier JB, Emanuelsson O, Kalume DE, Ytterberg J, Friso G, Rudella A, Liberles DA, Söderberg L, Roepstorff P, von Heijne G, van Wijk KJ. Central functions of the lumenal and peripheral thylakoid proteome of Arabidopsis determined by experimentation and genome-wide prediction. Plant Cell. 2002; 14: 211-36.https://doi.org/10.1105/tpc.010304

13. Schubert M, Petersson UA, Hass BJ, Funk C, Schröder WP, Kieselbach T. Proteome map of the chloroplast lumen of Arabidopsis thaliana. J Biol Chem. 2002; 277: 835465.https://doi.org/10.1074/jbc.M108575200

14. Zybailov B, Rutschow H, Friso G, Rudella A, Emanuelsson O, Sun Q, van Wijk KJ. Sorting signals, Nterminal modifications and abundance of the chloroplast proteome. PLoS One. 2008; 3 : e1994.https://doi.org/10.1371/journal.pone.0001994 
15. Lima A, Lima S, Wong JH, Phillips RS, Buchanan BB, Luan S. A redox-active FKBP-type immunophilin functions in accumulation of the photosystem II supercomplex in Arabidopsis thaliana. Proc Natl Acad Sci USA. 2006; 103: 12631-6.https://doi.org/10.1073/pnas.0605452103

16. Fu A, He Z, Cho HS, Lima A, Buchanan BB, Luan S. A chloroplast cyclophilin functions in the assembly and maintenance of photosystem II in Arabidopsis thaliana. Proc Natl Acad Sci USA. 2007; 104: 15947-52.https://doi.org/10.1073/pnas.0707851104

17. Sirpiö S, Khrouchtchova A, Allahverdiyeva Y, Hansson M, Fristedt R, Vener AV, Scheller HV, Jensen PE, Haldrup A, Aro EV. AtCYP38 ensures early biogenesis, correct assembly and sustenance of photosystem II. Plant J. 2008; 55: 639-51.https://doi.org/10.1111/j.1365-313X.2008.03532.x

18. He Z, Li L, Luan S. Immunophilins and parvulins. Superfamily of peptidyl prolyl isomerases in Arabidopsis. Plant Physiol. 2004; 134: 1248-1267.http://doi.org/10.1104/pp.103.031005

19. Fulgosi H, Vener AV, Altschmied L, Herrmann RG, Andersson B. A novel multi-functional chloroplast protein: identification of a $40 \mathrm{kDa}$ immunophilin-like protein located in the thylakoid lumen. EMBO J. 1998; 17: 1577-87.https://doi.org/10.1093/emboj/17.6.1577

20. Rokka, A, Aro EM, Herrmann RG, Andersson B, Vener AV. Dephosphorylation of photosystem II reaction center proteins in plant photosynthetic membranes as an immediate response to abrupt elevation of temperature. Plant Physiol. 2000; 123: 1525-36.https://doi.org/10.1104/pp.123.4.1525

21. Vener AV, Rokka A, Fulgosi H, Andersson B, Herrmann RG. A cyclophilin-regulated PP2A-like protein phosphatase in thylakoid membranes of plant chloroplasts. Biochemistry. 1999; 38: 1495565.https://doi.org/10.1021/bi990971v

22. Wang Y, Zeng L, Xing D. ROS-mediated enhanced transcription of CYP38 promotes the plant tolerance to high light stress by suppressing GTPase activation of Psb02. Front Plant Sci. 2015; 6: 777.https://doi.org/10.3389/fpls.2015.00777

23. Vasudevan D, Fu A, Luan S, Swaminathana K. Crystal structure of Arabidopsis cyclophilin38 reveals a previously uncharacterized immunophilin fold and a possible autoinhibitory mechanism. Plant Cell. 2012; 24: 2666-74.https://doi.org/10.1105/tpc.111.093781

24. Shapiguzov A, Edvardsson A, Vener AV. Profound redox sensitivity of peptidyl-prolyl isomerase activity in Arabidopsis thylakoid lumen. FEBS Lett. 2006; 580: 36716.https://doi.org/10.1016/j.febslet.2006.05.054

25. Edvardsson A, Shapiguzov A, Petersson UA, Schröder WP, Vener AV. Immunophilin AtFKBP13 sustains all peptidyl-prolyl isomerase activity in the thylakoid lumen from Arabidopsis thaliana deficient in AtCYP20-2. Biochemistry. 2007; 46: 9432-42.https://doi.org/10.1021/bi700426q 
26. Ingelsson B, Shapiguzov A, Kieselbach T, Vener AV. Peptidyl-prolyl isomerase activity in chloroplast thylakoid lumen is a dispensable function of immunophilins in Arabidopsis thaliana. Plant Cell Physiol. 2009; 50: 1801-14.https://doi.org/10.1093/pcp/pcp122

27. Obayashi T, Aoki Y, Tadaka S, Kagaya Y, Kinoshita K. ATTED-II in 2018: A plant coexpression database based on investigation of the statistical property of the mutual rank index. Plant Cell Physiol. 2018; 59: e3.https://doi.org/10.1093/pcp/pcx191

28. Szklarczyk, D, Gable AL, Lyon D, Junge A, Wyder S, Huerta-Cepas J, Simonovic M, Doncheva NT, Morris JH, Bork P, Jensen LJ, von Mering C. STRING v11: protein-protein association networks with increased coverage, supporting functional discovery in genome-wide experimental datasets. Nucleic Acids Res. 2019; 47: D607-13.https://doi.org/10.1093/nar/gky1131

29. Lu C, Xin Z, Ren Z, Miquel M, Browse J. An enzyme regulating triacylglycerol composition is encoded by the ROD1 gene of Arabidopsis. Proc Natl Acad Sci USA. 2009; 106: 1883742.https://doi.org/10.1073/pnas.0908848106

30. Satoh K, Yamamoto Y. The carboxyl-terminal processing of precursor D1 protein of the photosystem II reaction center. Photosynth Res. 2007; 94: 203-15.https://doi.org/10.1007/s11120-007-9191-z

31. Che Y, Fu A, Hou X, McDonald K, Buchanan BB, Huang W, Luan S. C-terminal processing of reaction center protein D1 is essential for the function and assembly of photosystem II in Arabidopsis. Proc Natl Acad Sci USA. 2013; 110: 16247-52.https://doi.org/10.1073/pnas.1313894110

32. Sun X, Peng L, Guo J, Chi W, Ma J, Lu C, Zhang L. Formation of DEG5 and DEG8 complexes and their involvement in the degradation of photodamaged photosystem II reaction center D1 protein in Arabidopsis. Plant Cell. 2007; 19: 1347-61.https://doi.org/10.1105/tpc.106.049510

33. Basak I, Pal R, Patil KS, Dunne A, Ho HP, Lee S, Diluka P, Maple-Grødem J, Odell M, Chang EJ, Larsen JP, Møller SG. Arabidopsis AtPARK13, which confers thermotolerance, targets misfolded proteins. J Biol Chem. 2014; 289: 14458-69.https://doi.org/10.1074/jbc.m114.548156

34. Van Buer J, Cvetkovic J, Baier M. Cold regulation of plastid ascorbate peroxidases serves as a priming hub controlling ROS signaling in Arabidopsis thaliana. BMC Plant Bio. 2016; 16(1): 163.https://doi.org/10.1186/s12870-016-0856-7

35. Wang YY, Hecker AG, Hauser BA. The APX4 locus regulates seed vigor and seedling growth in Arabidopsis thaliana. Planta. 2014; 239: 909-19.https://doi.org/10.1007/s00425-014-2025-2

36. Sirpiö S, Allahverdiyeva Y, Suorsa M, Paakkarinen V, Vainonen J, Battchikova N, Aro EM. TLP18.3, a novel thylakoid lumen protein regulating photosystem II repair cycle. Biochem J. 2007; 406: 41525.https://doi.org/10.1042/bj20070460 
37. Wu HY, Liu MS, Lin TP, Cheng YS. Structural and functional assays of AtTLP18.3 identify its novel acid phosphatase activity in thylakoid lumen. Plant Physiol. 2011; 157: 101525.https://doi.org/10.1104/pp.111.184739

38. Fields S, Song O. A novel genetic system to detect protein-protein interactions. Nature. 1989; 340: 245-6.https://doi.org/10.1038/340245a0

39. Ausubel FM, Brent R, Kingston RE, Moore DD, Seidman JG, Smith JA, Struhl K. Current Protocols in Molecular Biology. John Wiley, New York. 1990.

40. Shi LX, Schröder WP. The low molecular mass subunits of the photosynthetic supracomplex, photosystem II. Biochim Biophys Acta. 2004; 1608: 75-

96.https://doi.org/10.1016/j.bbabio.2003.12.004

41. Loll B, Kern J, Saenger W, Zouni A, Biesiadka J. Towards complete cofactor arrangement in the $3.0 \AA$ resolution structure of photosystem II. Nature. 2005; 438: 1040-

4.https://doi.org/10.1038/nature04224

42. Amunts A, Drory O, Nelson N. The structure of a plant photosystem I supercomplex at $3.4 \AA$ resolution. Nature. 2007; 447: 58-63.https://doi.org/10.1038/nature05687

43. Stroebel D, Choquet Y, Popot JL, Picot D. An atypical haem in the cytochrome b6f complex. Nature. 2003; 426, 413-8.https://doi.org/10.1038/nature02155

44. Sparkes IA, Runions J, Kearns, A, Hawes C. Rapid, transient expression of fluorescent fusion proteins in tobacco plants and generation of stably transformed plants. Nat Protoc. 2006; 1: 201925.https://doi.org/10.1038/nprot.2006.286

45. Hao Y, Oh E, Choi G, Liang Z, Wang ZY. Interactions between HLH and bHLH factors modulate lightregulated plant development. Mol Plant. 2012; 5: 688-97.https://doi.org/10.1093/mp/sss011

\section{Tables}

Table 1. Proteins co-expressed with AtCYP38 identified by ATTED-II. 


\begin{tabular}{|c|c|c|c|}
\hline Locus & Protein & Description & Location \\
\hline At1g20810 & FKBP18 & $\begin{array}{l}\text { FKBP-like peptidyl-prolyl cis-trans isomerase family } \\
\text { protein }\end{array}$ & $\begin{array}{l}\text { Thylakoid } \\
\text { Lumen }\end{array}$ \\
\hline At1g76450 & PPL & Photosystem II OEC PsbP family protein & $\begin{array}{l}\text { Thylakoid } \\
\text { Lumen }\end{array}$ \\
\hline At2g43560 & $\begin{array}{l}\text { FKBP16- } \\
3\end{array}$ & $\begin{array}{l}\text { FKBP-like peptidyl-prolyl cis-trans isomerase family } \\
\text { protein }\end{array}$ & $\begin{array}{l}\text { Thylakoid } \\
\text { Lumen }\end{array}$ \\
\hline At2g44920 & PRP & Pentapeptide-repeat protein in thylakoid lumen & $\begin{array}{l}\text { Thylakoid } \\
\text { Lumen }\end{array}$ \\
\hline At3g56650 & PPD6 & PSBP-domain protein 6 & $\begin{array}{l}\text { Thylakoid } \\
\text { Lumen }\end{array}$ \\
\hline At4g09010 & TAPX4 & Thylakoid ascorbate peroxidase 4, thylakoid lumen 29 & $\begin{array}{l}\text { Thylakoid } \\
\text { Lumen }\end{array}$ \\
\hline At5g52970 & TLP15 & Thylakoid lumen $15.0 \mathrm{kDa}$ protein & $\begin{array}{l}\text { Thylakoid } \\
\text { Lumen }\end{array}$ \\
\hline At5g53490 & TLP17.4 & $\begin{array}{l}\text { Thylakoid lumen } 17.4 \mathrm{kDa} \text { protein, putative } \\
\text { pentapeptide protein }\end{array}$ & $\begin{array}{l}\text { Thylakoid } \\
\text { Lumen }\end{array}$ \\
\hline At1g67700 & HHL1 & $\begin{array}{l}\text { Involved in protection of photosystem II from } \\
\text { photodamage }\end{array}$ & $\begin{array}{l}\text { Thylakoid } \\
\text { Membrane }\end{array}$ \\
\hline At1g08520 & CHLD & Magnesium chelatase $\mathrm{D}$ subunit, $\mathrm{CHLD}$ & $\begin{array}{l}\text { Chloroplast } \\
\text { Stroma }\end{array}$ \\
\hline At1g80380 & GLYK & $\begin{array}{l}\text { P-loop containing nucleoside triphosphate hydrolases } \\
\text { superfamily protein }\end{array}$ & $\begin{array}{l}\text { Chloroplast } \\
\text { Stroma }\end{array}$ \\
\hline At2g47940 & DEG2 & DEGP protease 2 & $\begin{array}{l}\text { Chloroplast } \\
\text { Stroma }\end{array}$ \\
\hline At2g36990 & SIGF & RNA polymerase sigma-subunit $F$ & $\begin{array}{l}\text { Chloroplast } \\
\text { Stroma }\end{array}$ \\
\hline At3g23700 & SRRP1 & S1 RNA-binding ribosomal Protein 1 & $\begin{array}{l}\text { Chloroplast } \\
\text { Stroma }\end{array}$ \\
\hline At4g01800 & AGY1 & Albino or grassy yellow 1 , has ATPase activity & $\begin{array}{l}\text { Chloroplast } \\
\text { Stroma }\end{array}$ \\
\hline At5g03940 & CPSRP54 & Chloroplast signal recognition particle $54 \mathrm{kDa}$ subunit & $\begin{array}{l}\text { Chloroplast } \\
\text { Stroma }\end{array}$ \\
\hline At4g15110 & CYP97B3 & $\begin{array}{l}\text { Cytochrome P450, family } 97 \text {, subfamily B, polypeptide } \\
3\end{array}$ & $\begin{array}{l}\text { Chloroplast } \\
\text { Stroma }\end{array}$ \\
\hline At4g01690 & PP01 & Protoporphyrinogen oxidase & $\begin{array}{l}\text { Chloroplast } \\
\text { Stroma }\end{array}$ \\
\hline At4g32590 & FDL & 2Fe-2S ferredoxin-like superfamily protein & $\begin{array}{l}\text { Chloroplast } \\
\text { Stroma }\end{array}$ \\
\hline
\end{tabular}


Table 2. Proteins functionally related to AtCYP38 identified by STRING.

\begin{tabular}{|lllll|}
\hline Locus & Protein & Description & Location \\
\hline At1g54780 & TLP18.3 & Thylakoid lumen protein 18.3 & Thylakoid Lumen \\
\hline At3g26060 & PRXQ & Thioredoxin superfamily protein & Thylakoid Lumen \\
\hline At4g02530 & MPH2 & Maintenance of photosystem Il under high light 2 & Thylakoid Lumen \\
\hline At5g45680 & FKBP13 & FKBP-type Peptidyl-prolyl cis-trans isomerase & Thylakoid Lumen \\
\hline At1g75690 & LQY1 & Low quantum yield of photosystem II 1 & Thylakoid Membrane \\
\hline At4g09650 & ATPD & ATP synthase subunit delta & Thylakoid Membrane \\
\hline At1g35680 & RPL21C & Chloroplast ribosomal protein L21 & Chloroplast Stroma \\
\hline At3g26900 & SKL1 & Probable inactive shikimate kinase like 1 & Chloroplast Stroma \\
\hline At3g63140 & CSP41A & Chloroplast stem-loop binding protein of 41 kDa & Chloroplast Stroma \\
\hline At5g47190 & PRPL19 & Plastid ribosomal proteins of the 50S subunit 19 & Chloroplast Stroma \\
\hline
\end{tabular}

Table 3. Interacting proteins of the mature full-length AtCYP38 identified by genome wide c-DNA library screening. 


\begin{tabular}{|llll|}
\hline Locus & Name & Description & Location \\
\hline At1g06680 & $\begin{array}{l}\text { PSBP- } \\
1\end{array}$ & Regulation of oxygen evolution & $\begin{array}{l}\text { Thylakoid } \\
\text { Lumen }\end{array}$ \\
At3g47070 & TSP9 & Thylakoid soluble phosphoprotein TSP9 & $\begin{array}{l}\text { Thylakoid } \\
\text { Lumen }\end{array}$ \\
\hline At5g39830 & DEG8 & Cleavage of photodamaged D2 protein of photosystem II & $\begin{array}{l}\text { Thylakoid } \\
\text { Lumen }\end{array}$ \\
\hline At5g02160 & FIP & FTSH5 interacting protein & $\begin{array}{l}\text { Thylakoid } \\
\text { Membrane }\end{array}$ \\
\hline At3g54900 & GRXCP & $\begin{array}{l}\text { Arabidopsis PICOT protein. It activates CAX1 gene } \\
\text { calcium transport activity }\end{array}$ & $\begin{array}{l}\text { Chloroplast } \\
\text { Stroma }\end{array}$ \\
\hline At4g25100 & FSD1 & Fe superoxide dismutase & $\begin{array}{l}\text { Chloroplast } \\
\text { Stroma }\end{array}$ \\
\hline At4g26530 & FBA5 & Fructose-bisphosphate aldolase activity & $\begin{array}{l}\text { Chloroplast } \\
\text { Stroma }\end{array}$ \\
\hline At5g20720 & CPN21 & Chloroplast co-chaperonin with similarity to E.coliGroES & $\begin{array}{l}\text { Chloroplast } \\
\text { Stroma }\end{array}$ \\
\hline
\end{tabular}

Table 4. Interacting proteins of the AtCYP38 N-terminal domain identified by genome wide c-DNA library screening.

\begin{tabular}{|llll|}
\hline Locus & Name & Description & Location \\
\hline At4g26530 & FBA5 & Fructose-bisphosphate aldolase activity & $\begin{array}{l}\text { Chloroplast } \\
\text { Stroma }\end{array}$ \\
\hline At1g72370 & AP40 & $\begin{array}{l}\text { Acidic protein associated to 40S ribosomal subunit of } \\
\text { ribosomes }\end{array}$ & Cytoplasm \\
\hline At1g68560 & XYL1 & $\begin{array}{l}\text { Bifunctional alpha-l-arabinofuranosidase/beta-d- } \\
\text { xylosidase }\end{array}$ & Cell Wall \\
\hline At5g15090 & VDAC3 & $\begin{array}{l}\text { Involved in metabolite exchange between the organelle } \\
\text { and the cytosol }\end{array}$ & Cell Wall \\
\hline
\end{tabular}

Table 5. Interacting proteins of the AtCYP38 C-terminal domain identified by genome wide c-DNA library screening. 


\begin{tabular}{|c|c|c|c|}
\hline Locus & Name & Description & Location \\
\hline At1g06680 & PSBP-1 & $\begin{array}{l}\text { Photosystem II extrinsic protein and participates in } \\
\text { the regulation of oxygen evolution }\end{array}$ & $\begin{array}{l}\text { Thylakoid } \\
\text { Lumen }\end{array}$ \\
\hline At1g20340 & PETE2 & Plastocyanin 2 & $\begin{array}{l}\text { Thylakoid } \\
\text { Lumen }\end{array}$ \\
\hline At3g01480 & AtCYP38 & $\begin{array}{l}\text { Assembly and maintenance of photosystem II } \\
\text { supercomplexes }\end{array}$ & $\begin{array}{l}\text { Thylakoid } \\
\text { Lumen }\end{array}$ \\
\hline At1g29920 & LHCB1.1/CAB2 & Chlorophyll binding & $\begin{array}{l}\text { Thylakoid } \\
\text { Membrane }\end{array}$ \\
\hline At1g29910 & LHCB1.2/CAB3 & Chlorophyll binding & $\begin{array}{l}\text { Thylakoid } \\
\text { Membrane }\end{array}$ \\
\hline At1g55670 & PSAG & Photosystem I subunit G & $\begin{array}{l}\text { Thylakoid } \\
\text { Membrane }\end{array}$ \\
\hline At2g34420 & LHCB1.5/LHB1B2 & Chlorophyll binding & $\begin{array}{l}\text { Thylakoid } \\
\text { Membrane }\end{array}$ \\
\hline At3g15820 & ROD1 & Diacylglycerol choline phosphotransferase activity & $\begin{array}{l}\text { Thylakoid } \\
\text { Membrane }\end{array}$ \\
\hline At4g03280 & PETC & Cytochrome b6f complex & $\begin{array}{l}\text { Thylakoid } \\
\text { Membrane }\end{array}$ \\
\hline At5g01530 & LHCB4.1 & Chlorophyll binding & $\begin{array}{l}\text { Thylakoid } \\
\text { Membrane }\end{array}$ \\
\hline At1g58380 & XW6 & Structural constituent of ribosome & $\begin{array}{l}\text { Chloroplast } \\
\text { Stroma }\end{array}$ \\
\hline At1g67090 & RBCA1A & $\begin{array}{l}\text { Encodes a member of the Rubisco small subunit } \\
\text { (RBCS) multigene family }\end{array}$ & $\begin{array}{l}\text { Chloroplast } \\
\text { Stroma }\end{array}$ \\
\hline At1g68010 & HPR & Hydroxypyruvate reductase & $\begin{array}{l}\text { Chloroplast } \\
\text { Stroma }\end{array}$ \\
\hline At5g38410 & RBCS3B & $\begin{array}{l}\text { Monooxygenase activity, ribulose-bisphosphate } \\
\text { carboxylase activity }\end{array}$ & $\begin{array}{l}\text { Chloroplast } \\
\text { Stroma }\end{array}$ \\
\hline At5g38420 & RBCS2B & $\begin{array}{l}\text { Monooxygenase activity, ribulose-bisphosphate } \\
\text { carboxylase activity }\end{array}$ & $\begin{array}{l}\text { Chloroplast } \\
\text { Stroma }\end{array}$ \\
\hline
\end{tabular}

Table 6. Interacting proteins of the AtCYP38 C-terminal domain identified by lumen protein library screening. 


\begin{tabular}{|c|c|c|c|}
\hline Locus & Name & Description & Location \\
\hline ArthCP016 & PSBM & Photosystem II intrinsic M subunit & $\begin{array}{l}\text { Thylakoid } \\
\text { Membrane }\end{array}$ \\
\hline ArthCP035 & CYTF & Cytb6f complex Cytf subunit & $\begin{array}{l}\text { Thylakoid } \\
\text { Membrane }\end{array}$ \\
\hline At2g28800 & ALB3 & $\begin{array}{l}\text { Protein translocation across thylakoid } \\
\text { membrane }\end{array}$ & $\begin{array}{l}\text { Thylakoid } \\
\text { Membrane }\end{array}$ \\
\hline ArthCP018 & CP43 & E loop of PSII CP43 subunit & $\begin{array}{l}\text { Thylakoid } \\
\text { Membrane }\end{array}$ \\
\hline ArthCP049 & CP47 & E loop of PSII CP47 subunit & $\begin{array}{l}\text { Thylakoid } \\
\text { Membrane }\end{array}$ \\
\hline At1g31330 & PSAF & Lumen loop of PSI PSAF subunit & $\begin{array}{l}\text { Thylakoid } \\
\text { Membrane }\end{array}$ \\
\hline At1g21500 & $\begin{array}{l}\text { Unknown } \\
\text { protein }\end{array}$ & $\begin{array}{l}\text { Thylakoid lumen protein with unknown } \\
\text { function }\end{array}$ & Thylakoid Lumen \\
\hline At2g23670 & $\begin{array}{l}\text { Unknown } \\
\text { protein }\end{array}$ & Homolog of synechocystis YCF37 & Thylakoid Lumen \\
\hline At2g26340 & $\begin{array}{l}\text { Unknown } \\
\text { protein }\end{array}$ & A Thylakoid lumen protein & Thylakoid Lumen \\
\hline At3g57680 & CTPB & D1 Carboxyl-terminal protease & Thylakoid Lumen \\
\hline At4g17740 & CTPA & D1 Carboxyl-terminal protease & Thylakoid Lumen \\
\hline At4g24930 & TLP17.9 & Thylakoid lumen 17.9 kDa protein, & Thylakoid Lumen \\
\hline At5g27660 & DEG14 & Arabidopsis PARK13 homolog & Thylakoid Lumen \\
\hline At5g46390 & CTPC & D1 Carboxyl-terminal protease & Thylakoid Lumen \\
\hline At5g52970 & TLP15 & Thylakoid lumen 15.0 kDa protein & Thylakoid Lumen \\
\hline
\end{tabular}

\section{Figures}




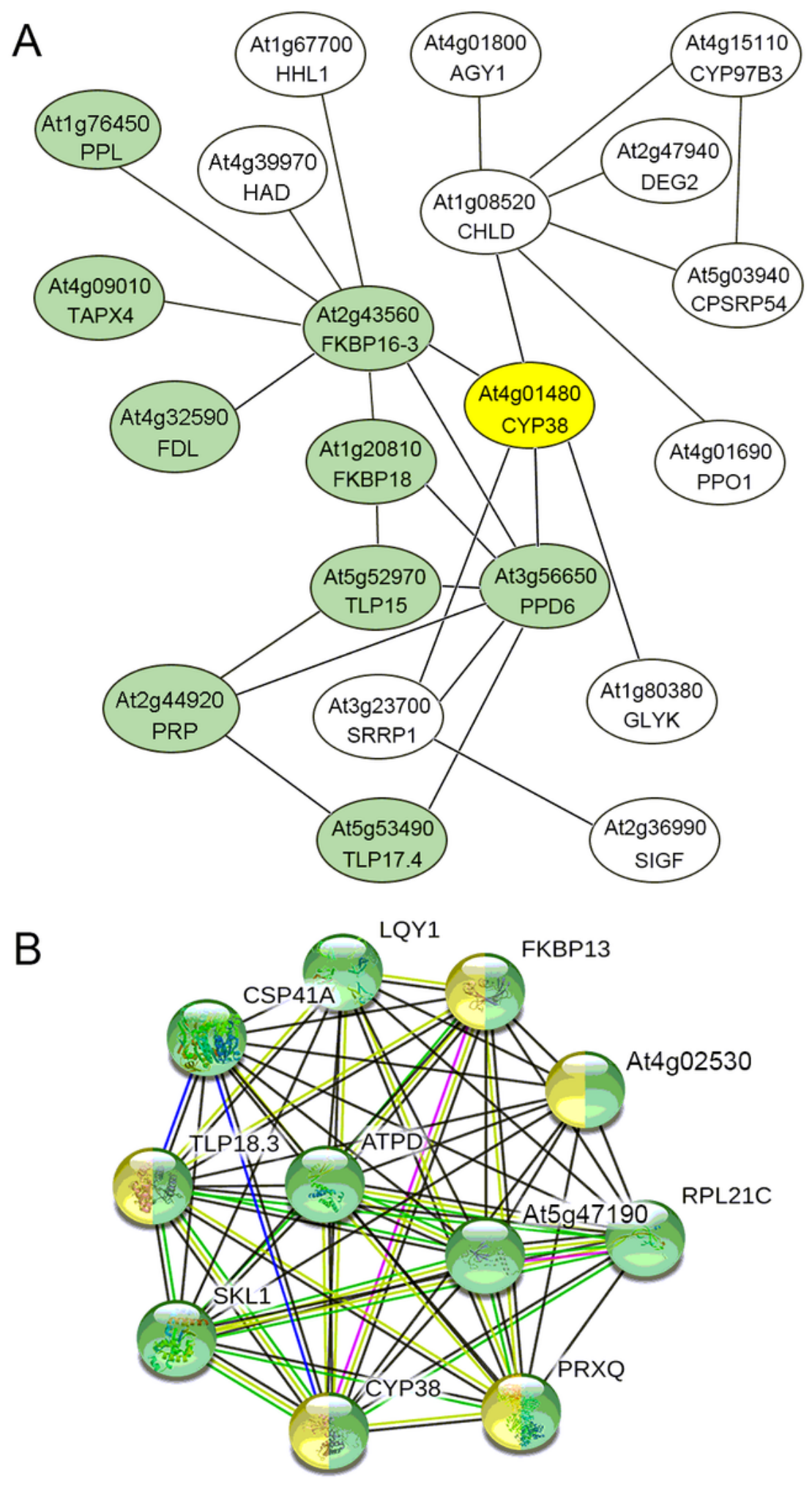

\section{Figure 1}

The correlation networks between AtCYP38 and its potential interacting proteins. A. The co-expression gene network using the AtCYP38 as query gene on the ATTED-II (http://atted.jp). AtCYP38, shown in yellow module, is co-expressed with multiple photosynthesis related genes. Thylakoid lumen localized proteins are colored in green. B. Protein-protein interaction network is generated by STRING search tool for CYP38 regulatory factors at highest confident score $(>0.970)$. Yellow modulate indicate the proteins 
which are predicted located in thylakoid lumen. Purple line represents the known interactions from experimentally determined. Green, blue, leaf green and black lines represent the predicted interactions from gene neighborhood, co-occurrence, text mining and co-expression, respectively.
A 1
9192

\section{Signal P}

\section{CYP38 mature protein (Full length)}
$\mathrm{N}$ terminal domain

\section{C terminal domain}
92
232236

B

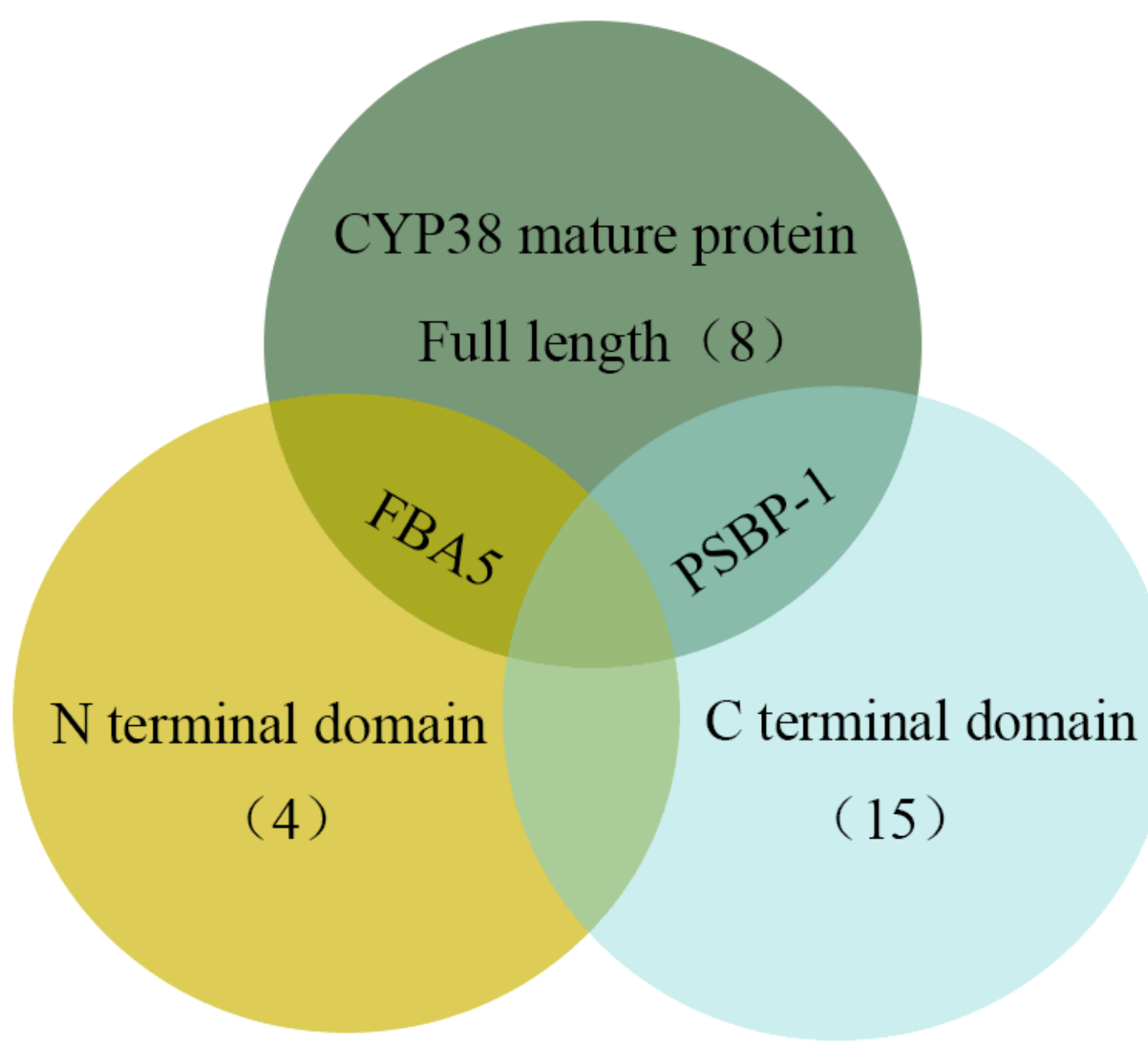

Figure 2

The schematic diagram of AtCYP38 protein different domains and interacting proteins identified by yeast two-hybrid screenings. A. Bar diagram represents the AtCYP38 different domains. AtCYP38 mature fulllength domain (amino acid residues from 92 to 437, without signal peptide), AtCYP38 N-terminal a-helical 
domain (amino acid residues from 92 to 232) and C-terminal cyclophilin $\beta$-sheet domain (amino acid residues from 236 to 437). B. Venn diagram showing the 25 potential AtCYP38-interacting partners are identified by YTH screening using 3 different domains.

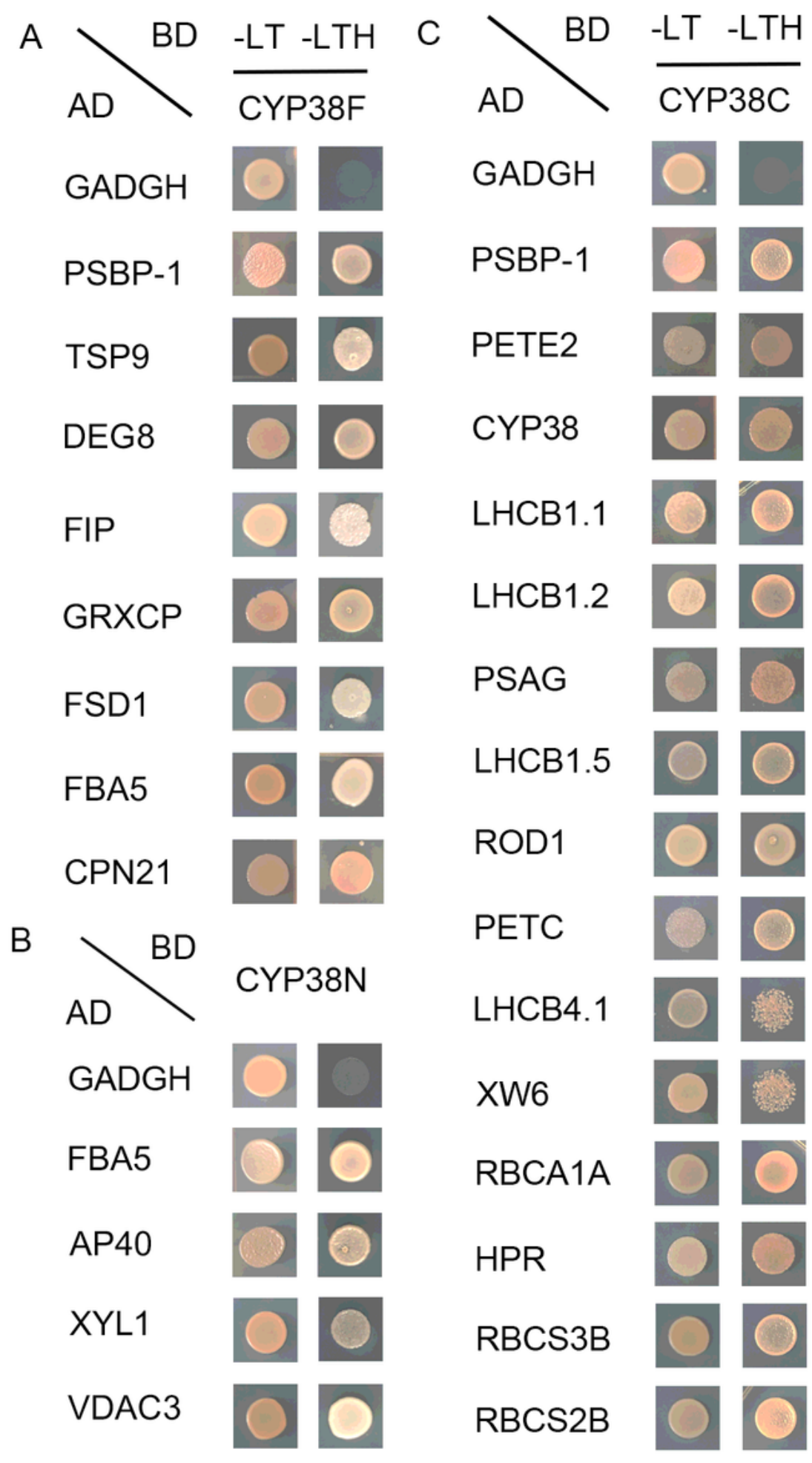

Figure 3

Confirmation of AtCYP38 candidate partners by yeast two-hybrid system. To test interaction results by yeast two-hybrid screening, both prey and bait vectors were co-transformed into yeast AH109 strain and 
inoculated onto SD/-Leu/Trp and SD/-Leu/Trp/His plates. A shows the confirmation of interaction between CYP38F domain and its screening results. B. Confirmation of interaction between CYP38N domain and its screening results. C. Confirmation of interaction between CYP38C domain and its screening results.

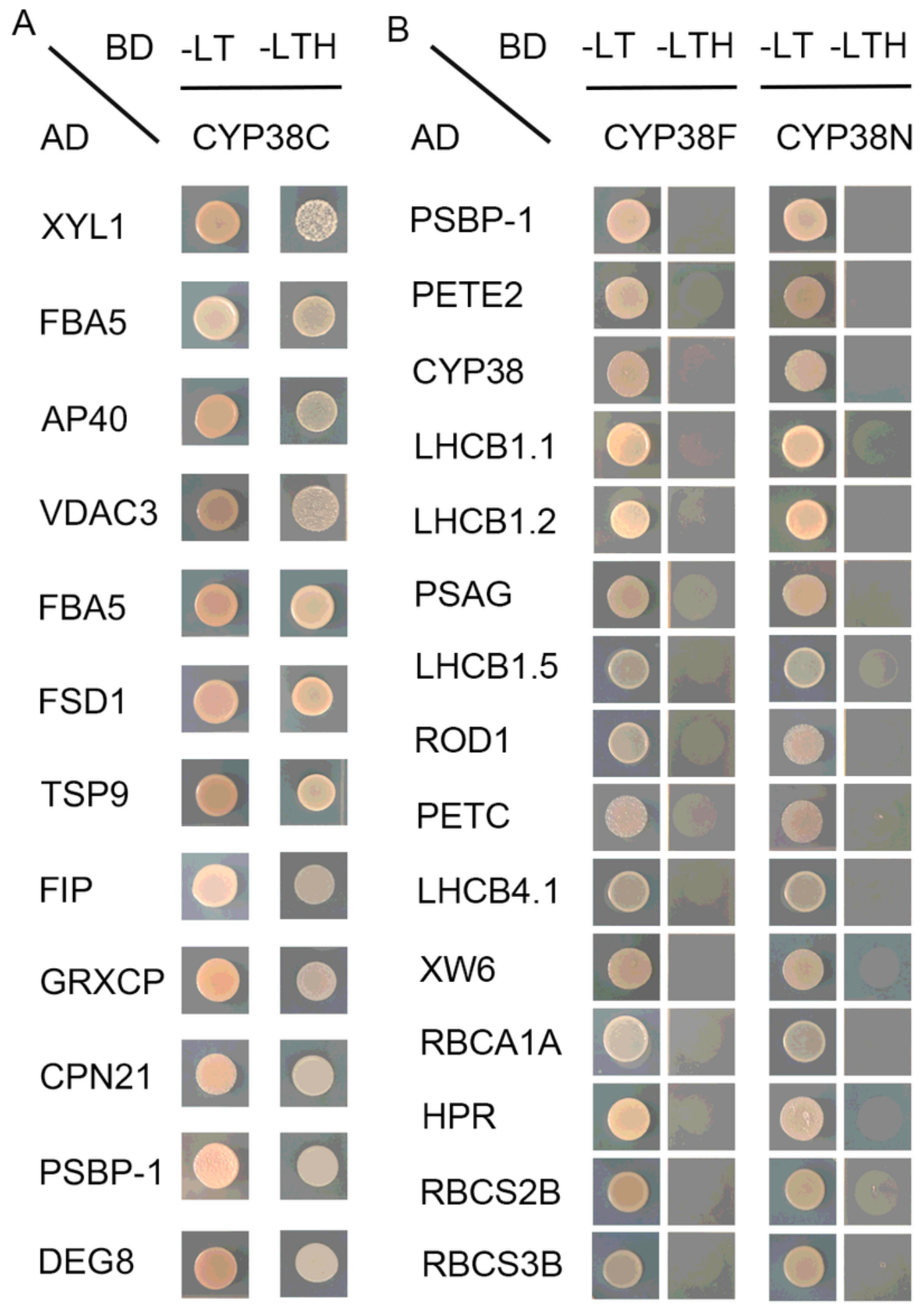

Figure 4 
Cross examination of interaction of potential targets with AtCYP38 different domains. A. Confirmation of interaction between CYP38C domain and the screening results which identified by CYP38F and CYP38N domains. B. Confirmation of interaction between CYP38F or CYP38N domain and screening results by using CYP38C protein as a bait.

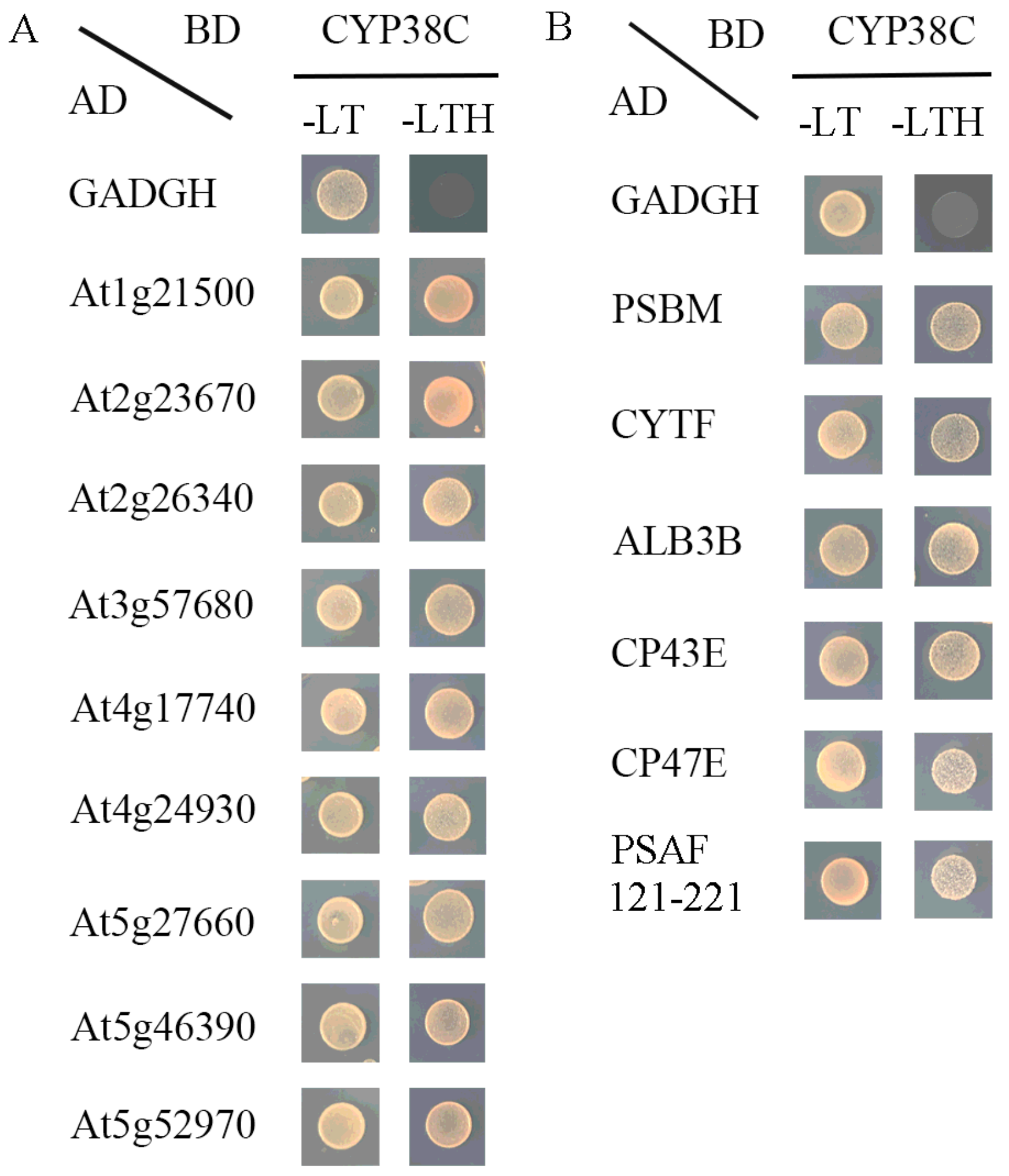

Figure 5 
Interacting proteins of the AtCYP38 $\mathrm{C}$ terminal domain by screening a thylakoid lumen mini-library. $\mathrm{A}$. Identification of potential interaction proteins in thylakoid lumen. B. Identification of potential interacting proteins on thylakoid membrane with lumenal fragments.

A

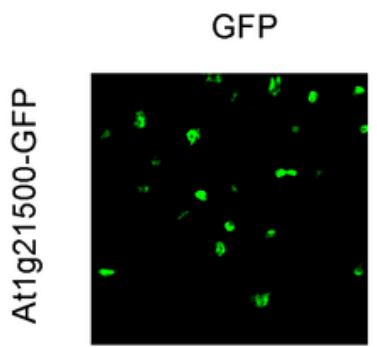

Chlorophyll

Merge
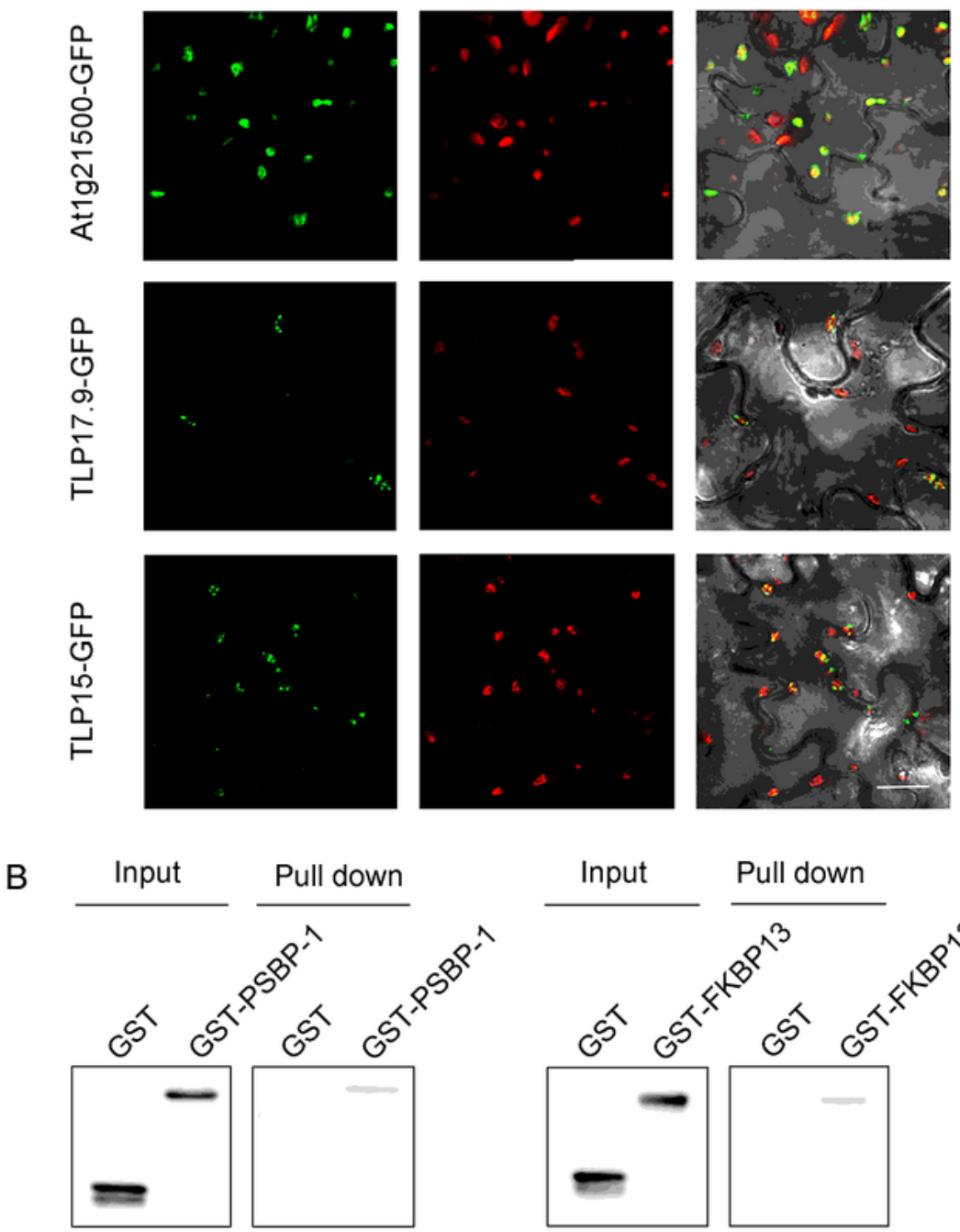

CYP38C-HIS

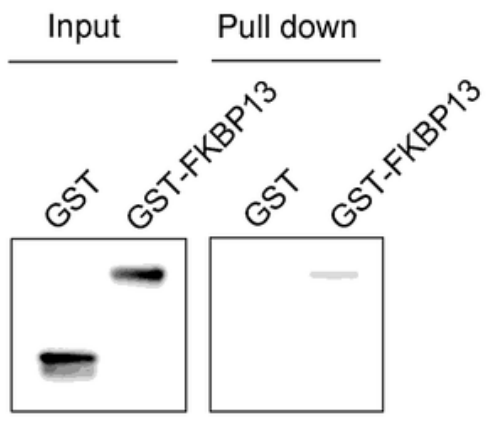

CYP38C-HIS

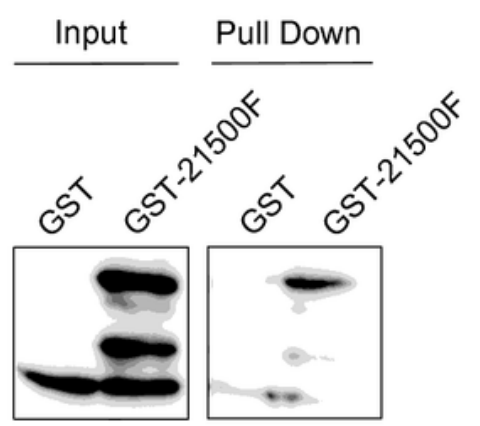

CYP38C-HIS

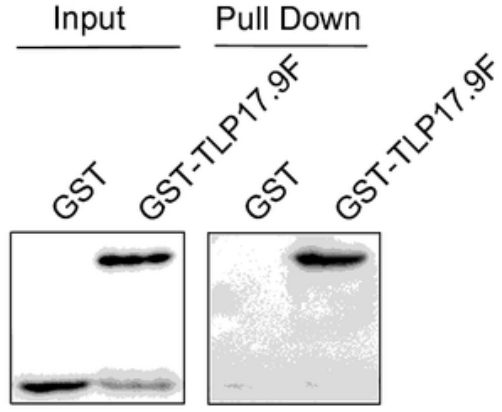

CYP38C-HIS

\section{Figure 6}

Subcellular localization of candidate proteins and the in vitro pull-down confirmation. A. At1g21500-GFP, At1g24930-GFP or At5g52970-GFP driven by 35S promoter and transiently expressed in the Nicotiana 
benthamiana epidermal cells (Scale bars:10 $\mu \mathrm{m}$ ). B. In vitro pull down assays showing interaction between CYP38C-HIS and GST-21500F, GST-TLP17.9F, GST-PSBP-1 or GST-FKBP13 proteins, respectively. GST, GST-21500F, GST-TLP17.9F, GST-PSBP-1 or GST-FKBP13 was pulled down by CYP38C-HIS immobilized on beads. Protein were detected by immunoblotting using GST antibody, the interaction of CYP38C and GST were used as a negative control.

\section{Supplementary Files}

This is a list of supplementary files associated with this preprint. Click to download.

- TableS1.docx

- originalgels.docx 